\title{
1.9-Å Resolution Structure of Fasciculin 1, an Anti-acetylcholinesterase Toxin from Green Mamba Snake Venom*
}

\begin{abstract}
Marie H. le Du $\ddagger \S$, Pascale Marchot $\uparrow \|$, Pierre E. Bougis $\llbracket \|$, and Juan C. Fontecilla-Camps $\ddagger \S^{* *}$
From the $\ddagger$ Laboratoire de Cristallographie et Cristallogénèse des Protéines du Département d'Ingéniérie et d'Etudes des Protéines, DSV, CENG, 85x, 38041 Grenoble Cedex, France and the 1 Centre National de la Recherche Scientifique, Unité de Recherche Associée 1455, Université d'Aix-Marseille II, Laboratoire de Biochimie, Faculté de Médecine, Secteur Nord, Bd. Pierre Dramard, 13326 Marseille, Cedex 15, France
\end{abstract}

The crystal structure of fasciculin 1, a potent acetylcholinesterase inhibitor from green mamba snake venom, has been solved by the multiple isomorphous replacement method complemented with anomalous scattering and subsequently refined at $1.9-\AA$ resolution. The overall structure of fasciculin is similar to those of the short $\alpha$-neurotoxins and cardiotoxins, with a dense core rich in disulfide bridges and three long loops disposed as the central fingers of a hand. A comparison of these three prototypic toxin types shows that fasciculin 1 has structural features that are intermediate between those of the other two molecules. Its core region, which can be defined as a continuous stretch of conserved residues, is very similar to that of erabutoxin $b$, whereas the orientation of its long loops resembles that of cardiotoxin $\mathrm{V}_{4}^{\mathrm{II}}$. This result introduces a new element in the study of phylogenetic relationships of snake toxins and suggests that, after divergency from an ancestral gene, convergent evolution may have played an important factor in the evolution of these proteins. In fasciculin 1, several arginine and lysine residues are well ordered and relatively exposed to the solvent medium and may play a role in the binding to the peripheral site of acetylcholinesterases.

Snake venoms contain a series of small proteins (60-70 residues long) that display a variety of toxic activities (Dufton and Hider, 1983, 1991). The best studied groups are the $\alpha$ neurotoxins, which bind postsynaptically to the nicotinic acetylcholine receptor (Changeux et al., 1970; Endo and Tamiya, 1991), and the cytotoxins or cardiotoxins, which are less well characterized with respect to their mode of action but are thought to interact with membranes or membrane components (Bougis et al., 1981; Harvey, 1985; Ménez et al., 1990; Dufton and Hider, 1991). The $\alpha$-neurotoxins have been divided into two groups: short toxins with, typically, 62 resi-

* The costs of publication of this article were defrayed in part by the payment of page charges. This article must therefore be hereby marked "advertisement" in accordance with 18 U.S.C. Section 1734 solely to indicate this fact.

The structure factor amplitudes, final atomic coordinates, and temperature factors have been deposited with the Protein Data Bank, Brookhaven National Laboratory, Upton, $N Y$.

$\S$ Present address: Laboratoire de Cristallographie et Cristallogénèse des Protéines, Institut de Biologie Structurale, 41, Avenue des Martyrs, 38027 Grenoble, Cedex 1, France.

$\|$ Supported in part by the Délégation aux Recherches et aux Etudes Techniques and to the Association Française contre les Myopathies.

** To whom all correspondence and reprint requests should be addressed. Tel.: 33-76-88-59-18; Fax: 33-76-51-88-22. dues and four disulfide bridges, and long toxins comprising about 70 amino acids and four or five disulfide bridges (Endo and Tamiya, 1987). Differences in the primary structures between both long and short $\alpha$-neurotoxins and cardiotoxins can amount to up to $70 \%$. Nevertheless, $x$-ray crystallography studies have shown that all these molecules have a common three-dimensional folding pattern: a core consisting of a series of short loops and four disulfide bridges, from which three longer loops protrude that are roughly oriented as the central fingers of a hand (Low et al., 1976; Tsernoglou and Petsko, 1976; Love and Stroud, 1986; Rees et al., 1987; Smith et al., 1988, Betzel et al., 1991). Similar results have been obtained through NMR studies (Labhardt et al., 1988; Steinmetz et al., 1988; Laplante et al., 1990; Yu et al., 1990; Oswald et al., 1991). Superposition of erabutoxin b, a short $\alpha$-neurotoxin, and cardiotoxin $\mathrm{V}_{4}^{\mathrm{II}}$ indicates that, although the disulfide-rich core is conserved, the orientation of the long loops can differ considerably (Rees et al., 1990). These differences, which are the consequence of variations in the amino acid sequences of the loops, should result in the correct positioning of functionally important residues and modulate the toxic activity. A similar situation is found in the case of scorpion toxins (Fontecilla-Camps, 1989).

An additional group of basic snake toxins capable of inducing extensive muscular fibrillation has been described (Viljoen and Botes, 1973). These small proteins of about $6750 \mathrm{Da}$, which have been called fasciculins, are very potent inhibitors of most synaptic acetylcholinesterases $\left(K_{i} \approx 10^{-10} \mathrm{M}\right)$ (Rodriguez-Ithurralde et al., 1983). They do not seem to bind directly to the active site of the enzyme; rather, they bind with a 1:1 stoichiometry to a peripheral site that is also the target of a series of small molecules (Taylor and Lappi, 1975; Harvey et al., 1984). Fasciculins are able to displace propidium, are displaced by $\mathrm{Ca}^{2+}$ and $\mathrm{Mg}^{2+}$, and have $K_{i}$ values independent of acetylcholine concentration (Cerveñanski et al., 1991a). The venom of the green mamba Dendroaspis angusticeps contains at least two fasciculins that are 61 residues long and differ at a single amino acid position (Karlsson et al., 1984). Another closely related molecule, toxin $\mathrm{C}$, has been purified from Dendroaspis polylepis polylepis (Joubert and Taljaard, 1978). Although some other similar proteins generally referred to as "angusticeps-type" toxins have been purified from mamba venoms, only the three proteins mentioned above show anti-acetylcholinesterase activity. The primary structures of these proteins and especially the distribution of their 8 cysteine residues suggest that they are structurally related to both short $\alpha$-neurotoxins and cardiotoxins.

We have initiated a series of crystallographic studies of fasciculins in order to establish the molecular basis of their mode of action and to compare their structures with those of 
neurotoxins and cardiotoxins. This comparison should shed further light on the mechanisms of protein evolution that result in structural differences and, by extension, different biological activities.

Tetragonal crystals of fasciculin 2, which belong to the space group $\mathrm{P}_{1} 2_{1} 2$ or its enantiomorph, have been reported by us and others (le Du et al., 1989; Sankar et al., 1989). Xray diffraction data collected from these crystals indicated the existence of significant mosaic spread and relatively limited diffracting power. This prompted us to attempt the structural study of fasciculin 1 . We report here the crystallization, $\mathbf{x}$-ray structure determination, and crystallographic refinement at 1.9-A resolution of this toxin. Similar crystals of fasciculin 1 , grown from thiocyanate solutions, have been obtained by Ménez and Ducruix (1991).

\section{MATERIALS AND METHODS}

Crystallization-Fasciculin 1, purified by the procedure described for fasciculin 2 (le Du et al., 1989), was subsequently crystallized using the hanging drop method (Wlodawer and Hodgson, 1975). The protein was dissolved at a concentration of $10 \mathrm{mg} / \mathrm{ml}$ in $100 \mathrm{mM}$ $\mathrm{NH}_{4}^{+} \mathrm{CH}_{3} \mathrm{COO}^{-}$and was mixed and equilibrated against a reservoir solution containing $20 \%$ saturation $\left(\mathrm{NH}_{4}\right)_{2} \mathrm{SO}_{4}$ and buffered with 100 $\mathrm{mM} \mathrm{MES},{ }^{1} \mathrm{pH}$ 6.0. Best results were obtained when the ratio of protein solution to reservoir solution in the drop was initially $1: 2$ and the volumes were 2 and $4 \mu \mathrm{l}$, respectively. All the experiments were carried out at $20^{\circ} \mathrm{C}$. The crystals, which grow as large prisms $(0.4 \times$ $0.4 \times 0.8 \mathrm{~mm}^{3}$ ), belong to the space group $\mathrm{P}_{4}, 2,2$ or its enantiomorph, $\mathrm{P}_{4} 2_{2} 2$, with $a=40.3 \AA$ and $c=81.3 \AA$. $V_{m}$ calculations indicate that there are eight protein molecules in the unit cell and approximately $50 \%$ solvent content in the crystals (Matthews, 1968).

Heavy Atom Derivatives - After several trials, the optimum mother liquor solution for soaking experiments was found to be composed of $25 \%$ saturation $\left(\mathrm{NH}_{4}\right)_{2} \mathrm{SO}_{4}$ and $50 \mathrm{mM} \mathrm{KCl}$, buffered with $100 \mathrm{mM}$ MES, pH 6.5. Of the 11 heavy atom salts tested, only three, $\mathrm{K}_{2} \mathrm{PtCl}_{4}$, $\mathrm{EtHgCl}$, and $\mathrm{K}_{2} \mathrm{OsCl}_{4}$, provoked significant changes in either precession photographs or data sets collected on a Xentronics/Siemens area detector. Adequate concentrations of the heavy atom salts were 0.5 $\mathrm{mM}$ for the platinum salt and $5 \mathrm{~mm}$ for the mercury salt. In both cases, the soaking time was $20 \mathrm{~h}$. Attempts to get a usable $\mathrm{K}_{2} \mathrm{OsCl}_{4}$ derivative proved unsuccessful.

Data Collection-Data from native and derivatized crystals were collected at room temperature on a Xentronics/Siemens area detector coupled to a Rigaku RU200 x-ray generator equipped with a graphite monochromator and a $0.3 \times 3-\mathrm{mm}^{2}$ focal spot size. In every case the collection time was adjusted so that approximately $1 \times 10^{6}$ counts were accumulated per frame with an $\omega$ oscillation range of $0.25^{\circ}$ (typical times were 60-180 s/frame, depending on crystal size and the effect of the heavy atom salt). Subsequently, the XENGEN v1.3 set of programs (Howard et al., 1987) was used to obtain unscaled intensities. Internal scaling of the various data sets was carried out using ROTAVATA and AGROVATA, and structure factors were calculated by TRUNCATE as implemented in the CCP4 programs package (Machin et al., 1984). Table I depicts a summary of data collection statistics. The heavy atom derivative structure factors were scaled to their corresponding native mates using the program ANSC. Both a scale factor and a relative temperature factor were used in the scaling.

Refinement of Heavy Atom Positions and Phase CalculationsDifference Patterson maps using $\left(F_{\mathrm{PH}}-F_{\mathrm{P}}\right)^{2}$ coefficients were calculated by the fast Fourier method. Both the platinum and mercury derivatives gave unambiguous single site solutions. Subsequently, the same result was obtained from anomalous difference Patterson maps (Blundell and Johnson (1976), and references therein). Initial refinement was carried out using centric data and the SELFH option of REFINE (Dodson, 1976; Machin et al., 1984). In order to relate both derivatives' sites to a common origin and to establish the correct space group enantiomorph, difference Fourier maps were calculated for the two derivatives using SIRAS phases in the customary way (Blundell and Johnson, 1976). This procedure indicated that the

${ }^{1}$ The abbreviations used are: MES, 4-morpholineethanesulfonic acid; SIRAS, single isomorphous replacement plus anomalous scattering; MIRAS, multiple isomorphous replacement plus anomalous scattering; SA, simulated annealing.
TABLE I

Data collection statistics

\begin{tabular}{|c|c|c|c|c|c|c|}
\hline & $\begin{array}{l}\text { Number } \\
\text { of ob- } \\
\text { served re- } \\
\text { flections }\end{array}$ & $\begin{array}{l}\text { Number } \\
\text { of } \\
\text { used } \\
\text { reflections }\end{array}$ & $\begin{array}{l}\text { Number } \\
\text { of unique } \\
\text { reflections }\end{array}$ & $\begin{array}{l}\text { Complete- } \\
\text { ness }\end{array}$ & $\begin{array}{c}\text { Resolution } \\
\text { limit }^{\sigma}\end{array}$ & $R_{\mathrm{sym}}^{b}$ \\
\hline & & & & & $\dot{A}$ & \\
\hline Native & 28,651 & 27,118 & 4,874 & 0.846 & 1.9 & 0.062 \\
\hline $\mathrm{K}_{2} \mathrm{PtCl}_{4}$ & 12,648 & 11,994 & 2,827 & 0.951 & 2.4 & 0.066 \\
\hline $\mathrm{EtHgCl}$ & 8,101 & 7,610 & 1,762 & 0.832 & 2.7 & 0.088 \\
\hline
\end{tabular}

${ }^{a}$ The crystal-to-detector distance was $120 \mathrm{~mm}$ in every case. Swing angles of 20,10 , and $8^{\circ}$ were used for native, platinum, and mercury derivative data collection, respectively.

$$
{ }^{b} R_{\mathrm{sym}}=\sum_{h}^{M} \sum_{0}^{N h}\left|I_{\mathrm{th}}-\langle I\rangle_{h}\right| /\left(\sum_{h}^{M} \sum_{0}^{N h}\langle I\rangle_{h}\right),
$$

where $N h=$ number of symmetry related reflections and $M=$ total number of equivalent $h k l$ sets.

\section{TABLE II}

\section{Heavy atom refinement statistics}

$R_{f}$ is the percent change between native $\left(F_{1}\right)$ and scaled derivative $\left(F_{2}\right)$ data $\left(\sum\left(\left|F_{1}\right|-\left|F_{2}\right|\right) / \sum\left|F_{1}\right|\right) . x, y, z$ are the fractional coordinates of the heavy atom; $\beta_{i, j}$ represent the anisotropic temperature factor. The relative occupancies are on an arbitrary scale. $R_{\mathrm{c}}$ is the Cullis $R$ factor $\left(\sum\left|F_{P H}-F_{P}\right|-f_{H}\left|/ \sum\right| F_{P H}-F_{P} \mid\right)$ for centric terms. $F_{H / E}$ is the average value of the heavy atom contribution divided by the lack-ofclosure error. Values in parentheses correspond to the $F_{H / E}$ ratios in the highest resolution data shell (3.03-2.7 $\AA$ for $\mathrm{K}_{2} \mathrm{PtCl}_{4}$ and $3.44-$ $3.03 \AA$ for $\mathrm{EtHgCl}$ ).

\begin{tabular}{|c|c|c|c|c|c|c|c|c|}
\hline & $R_{f}$ & $x$ & $y$ & $z$ & $\beta_{i, j}$ & $\begin{array}{l}\text { Relative } \\
\text { occupancy }\end{array}$ & $R_{\varsigma}$ & $F_{H / E}$ \\
\hline $\mathrm{K}_{2} \mathrm{PtCl}_{4}$ & 0.213 & 0.319 & 0.451 & 0.383 & $\begin{array}{r}0.0193 \\
0.0212 \\
0.0022 \\
0.0074 \\
-0.0017 \\
0.0011\end{array}$ & 10.47 & 0.523 & $\begin{array}{r}2.34 \\
(1.99)\end{array}$ \\
\hline $\mathrm{Et} \mathrm{HgCl}$ & 0.111 & 0.190 & 0.413 & 0.050 & $\begin{array}{r}0.0048 \\
-0.0031 \\
-0.0012 \\
0.0004 \\
0.0001 \\
0.0003\end{array}$ & 2.58 & 0.606 & $\begin{array}{r}1.54 \\
(1.39)\end{array}$ \\
\hline
\end{tabular}

actual space group was $\mathrm{P}_{1} 2_{1} 2$. The heavy atom sites were then refined, first independently and then jointly, using the program PHARE (Table II). The solvent flattening technique of Wang (1985) was applied to the MIRAS protein map using data to $2.7 . \AA$ resolution so that four cycles consisting of one envelope calculation and four solvent flattening runs were carried out with a $40 \%$ solvent content estimate. After each cycle, a new map was calculated using phases that were a combination of those obtained from the back-transformed flattened map and those calculated by the MIRAS method. This procedure resulted in a somewhat improved electron density map. The final $R$-factor, based on the back-Fourier transform of the solvent-flattened map, and the root mean square difference between the MIRAS and the combined phases were 0.194 and $19^{\circ}$, respectively.

Structure Solution and Refinement-Both the envelopes and minimaps calculated with the final combined phases were used in the tracing of the fasciculin 1 molecule. The envelopes were examined on a Silicon Graphics Personal IRIS $4 \mathrm{D} / 35$ system by means of the program TURBO FRODO (Roussel and Cambillau, 1989) and the minimaps were generated using the CCP4 version of the program PLUTO. After establishing the general molecular boundary as determined by the solvent flattening procedure, dummy atoms for several well defined segments were measured from the minimaps and examined by using computer graphics. The correct tracing was found by a combination of segment fitting and verification using the disulfiderich core of erabutoxin b (Low et al., 1976). Subsequently, the structure was built using computer graphics and the known amino acid 
a

FIG. 1. Stereo drawing of residues 34-37 depicting the associated electron density after the sixth cycle of SA refinement. Before $(a)$ and after (b) manual correction. The electron density map was contoured at the $1 \sigma$ level. This, as well as Figs. 2 and $4-6$, were generated using a Postcript ${ }^{\text {tis }}$ output of TURBO FRODO.
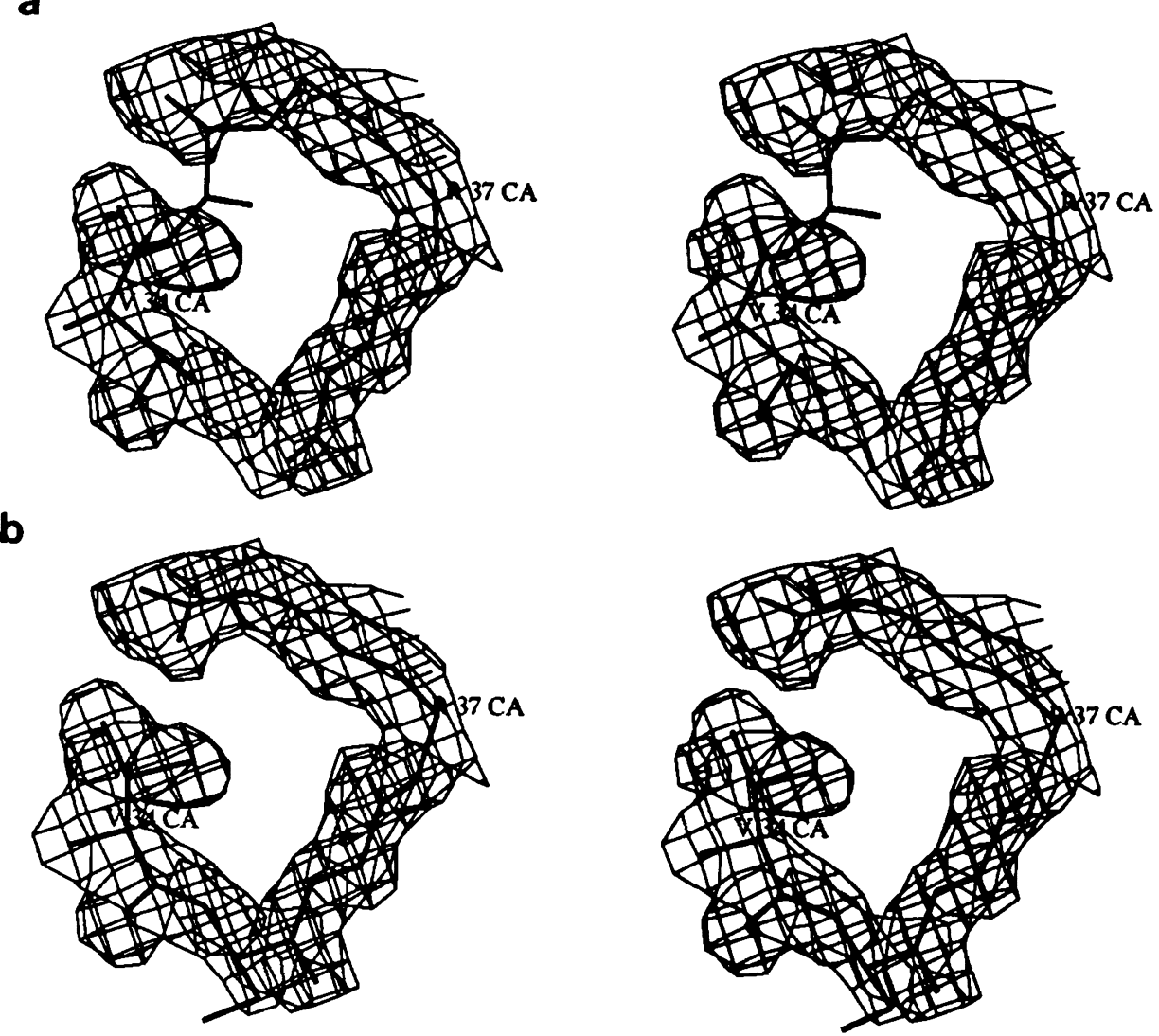

sequence of fasciculin 1 (Ducancel et al., 1991). Only the region comprising residues $6-13$ and the side chain of $A \mathrm{sn}^{21}$ appeared ill defined in the electron density map (but see below). At this point, a refinement of the protein model was initiated using the program $\mathrm{X}$ PLOR (Brünger, 1988). Eight cycles of SA were performed using the scheme outlined in the X-PLOR tutorial. The heating stage was applied during $1.5 \mathrm{ps}$ while the temperature was raised from 2000 to $3000 \mathrm{~K}$, and the cooling stage was carried out during $1.25 \mathrm{ps}$ to a final temperature of $300 \mathrm{~K}$. During this procedure, the starting resolution range, which was $8.0-3.0 \AA$, was gradually changed to $6.0-2.0 \AA$. A total of 20 additional energy minimization steps were then performed, in which the maximum resolution was set to $1.9 \AA$ and solvent molecules were added gradually. The model was periodically inspected and corrected using computer graphics and electron density maps with $\left(2 F_{o}-F_{c}\right),\left(F_{o}-F_{c}\right)$ and $-\left(F_{o}-F_{c}\right)$ coefficients $^{2}$ (Blundell and Johnson, 1976). Use of the program RHOFIT, ${ }^{3}$ which interpolates electron densities at atomic centers, helped to determine the problem regions and to optimize the positioning of several atoms in the Fourier difference maps. The fragment containing residues $34-37$, that was erroneously fitted during model building, was corrected after the sixth cycle of SA refinement. Although the resulting electron density showed very clearly the correct disposition for these amino acids, the problem was not spotted earlier due to the fact that all the atoms of the fragment moved to an incorrect, roughly matching, electron density during the initial SA refinement (Fig. 1). After correction of this error and one additional cycle of refinement, the $R$-factor dropped from 0.252 to 0.231 . Its current value is 0.173 for reflections with $F$ $>2.5 \sigma(F)$ between 8 - and $1.9-\AA$ resolution. Table III depicts the progress of the refinement procedure. The present model contains 59 water molecules with $B<62 \AA^{2}$ and a fixed occupancy of 1.0, and the mean $B$ values for main chain, side chain, and solvent are $13.6,14.7$, and $38.9 \AA^{2}$, respectively. The atomic model has root mean square deviations from ideality of $0.013 \AA$ for bond lengths, $2.89^{\circ}$ for bond

\footnotetext{
${ }^{2}$ Maps with $-\left(F_{0}-F_{c}\right)$ coefficients were instrumental in detecting negative density in the difference maps, since TURBO FRODO, as with many other versions of FRODO, does not depict negative electron density.

${ }^{3} \mathrm{~A}$. Volbeda, personal communication.
}

TABLE III

Model refinement

\begin{tabular}{ccccc}
\hline Cycle & Resolution & $\begin{array}{c}\text { Number } \\
\text { of reflec- } \\
\text { tions }\end{array}$ & $\begin{array}{c}\text { Number } \\
\text { of water } \\
\text { molecules }\end{array}$ & $R$-factor ${ }^{a}$ \\
\hline \multicolumn{5}{c}{ Simulated annealing } \\
\hline 0 & $8.0-3.0$ & 1453 & 0.545 \\
1 & $8.0-3.0$ & 1453 & 0.306 \\
3 & $8.0-2.5$ & 2481 & 0.274 \\
4 & $6.0-2.5$ & 2357 & 0.250 \\
5 & $6.0-2.0$ & 4358 & 0.260 \\
8 & $6.0-2.0$ & 4358 & 4 & 0.221 \\
\hline \multicolumn{5}{c}{ Energy minimization } \\
\hline 9 & $6.0-1.9$ & 4651 & 15 & 0.181 \\
28 & $8.0-1.9$ & 4775 & 60 & 0.173 \\
$28^{b}$ & $8.0-1.9$ & 4446 & 60 & \\
\hline \multirow{5}{*}{$R$-factor $=\sum_{l}^{n}\left(\left|F_{o}\right|-\left|F_{c}\right|\right) / \sum_{l}^{n}\left|F_{c}\right|}$. &
\end{tabular}

${ }^{n}$ Calculated with a $2.5 \sigma F$ cutoff.

angles, and $26.1^{\circ}$ for dihedral angles. A $(\Phi, \Psi)$ plot (Ramachandran and Mitra, 1976) of fasciculin 1 is shown in Fig. 2. The mean atomic coordinate error can be estimated to fall between 0.15 and $0.20 \AA$ (Luzzati, 1952). A complete account of the crystallographic refinement will be published elsewhere.

\section{RESULTS}

Atomic coordinates of cardiotoxin $\mathrm{V}_{4}^{\mathrm{II}}$ were kindly provided by $B$. Rees, while those of erabutoxin-b were obtained from the Brookhaven Protein Data Bank, entry 3EBX.

\section{Structure Description}

Fasciculin 1 appears as a slightly concave flat disc with a dense core containing four disulfide bridges and three long 


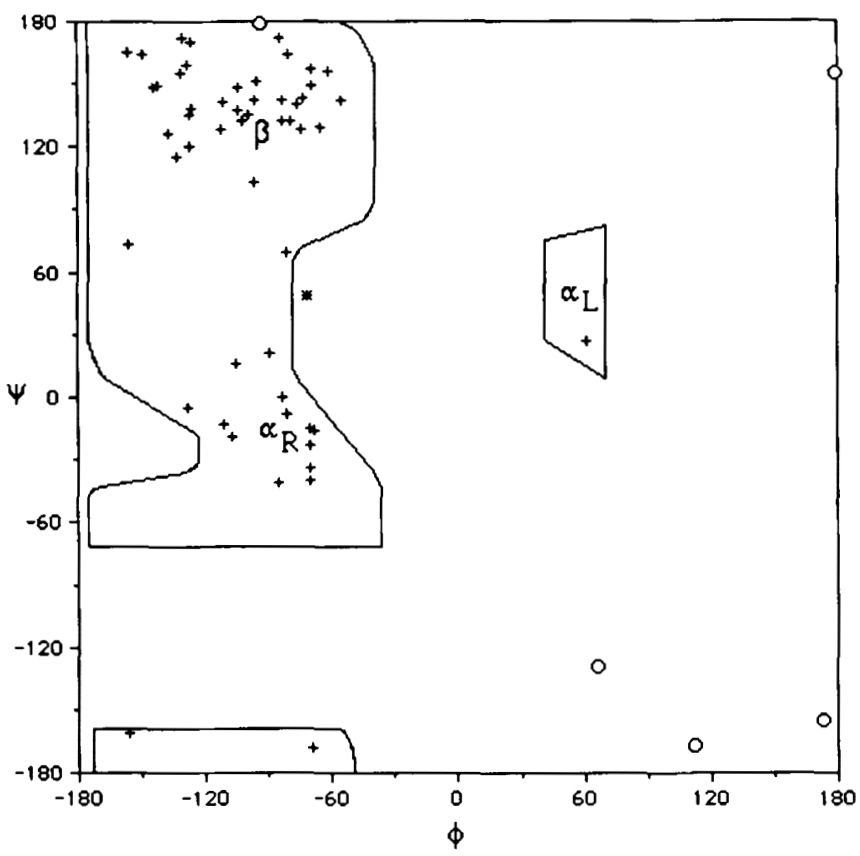

Fig. 2. Ramachandran plot of the refined structure of fasciculin 1. $O$, glycines; + , non-glycines. The asterisk represents $\operatorname{Arg}^{11}$.
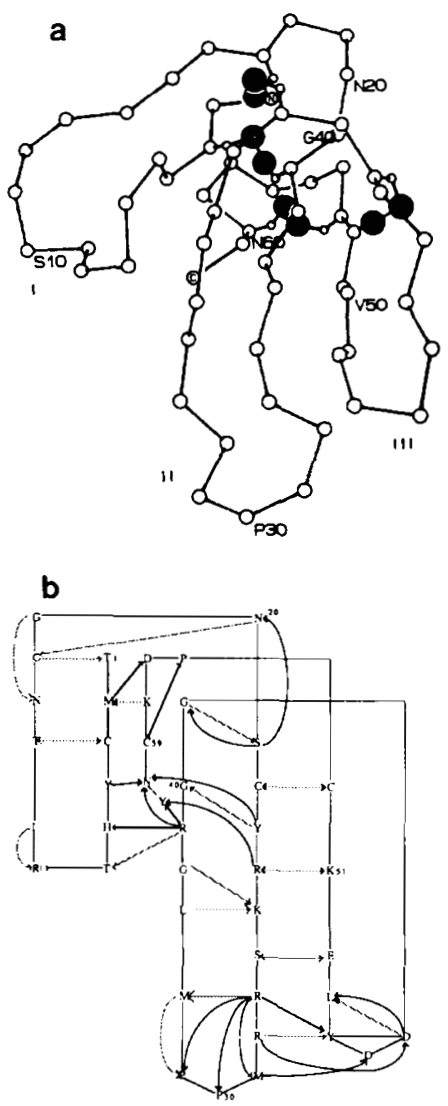

Fig. 3. $a, \mathrm{C}_{\mathrm{a}}$ backbone drawing of fasciculin 1. The sulfur atoms are represented by black circles, and the $\mathrm{N}$ and $\mathrm{C}$ termini are indicated. This drawing was generated using the program PLUTO (S. Motherwell, Cambridge Crystallographic Data Center, University Chemical Laboratory, Lensfield Rd., Cambridge, England). $b$, schematic representation of intramolecular hydrogen bonding. Arrows indicate donoracceptor direction. Dashed lines represent main chain-main chain interactions; solid lines depict interactions implicating at least one side chain.

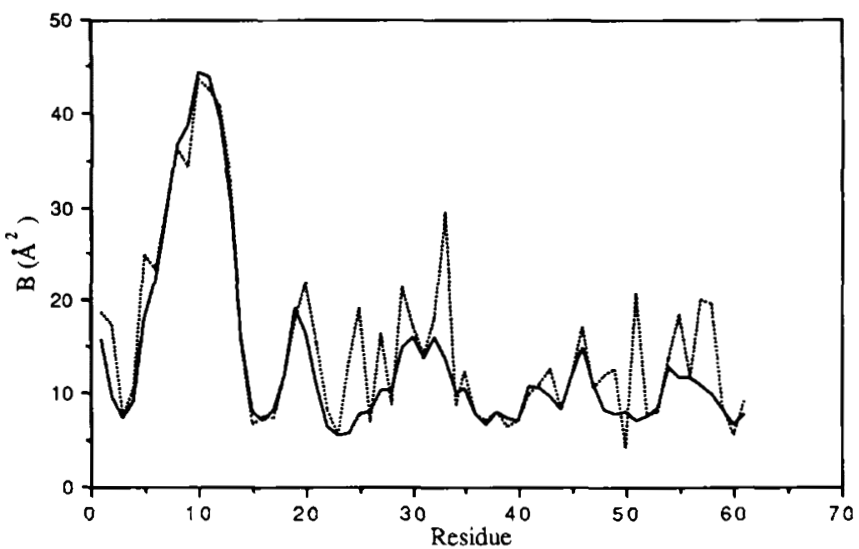

FIG. 4. Temperature factors for main (solid line) and side chain (dotted line) atoms of the refined model of fasciculin 1.

loops that emerge from it (Fig. 3). We have designated the long loops that are formed by residues $5-15,24-38$, and 4350 as loops I, II, and III, respectively, following the convention established for related molecules. The toxin contains two antiparallel $\beta$-sheets; one is three-stranded, formed by residues $22-27,34-39$, and $48-53$, and a second is a very short, two-stranded one consisting of residues $3-4$ and 14-15. There are also two class I $\beta$-turns at positions $17-20$ and 58-61 and a class II $\beta$-turn comprising residues $56-59$ (Schulz and Schirmer, 1979). A nonstandard $\beta$-turn (Richardson, 1981) is defined by residues $45-48$. The remaining two bends cannot be characterized in terms of well defined secondary structure; they correspond to the disordered region around residues 611 (mean $B=35 \AA^{2}$; see Fig. 4) and the zone comprising residues $30-33$. The bend regions of loops II and III are interconnected through a series of hydrogen bonds involving $\mathrm{Arg}^{27}, \mathrm{Arg}^{28}$, and $\mathrm{His}^{29}$ on one side and $\mathrm{Asp}^{45}, \mathrm{Asp}^{46}, \mathrm{Tyr}^{47}$, and $\mathrm{Glu}^{49}$ on the other (Figs. $3 b$ and 5). A complete account of the intramolecular hydrogen bonding is depicted in Fig. 1.

Two of the 5 proline residues present in fasciculin 1 are in the cis conformation (Fig. 6). Because of cis-Pro ${ }^{31}$, at the bend region of loop II, the carbonyl oxygen of residue 30 is located within hydrogen-bonding range of the $\mathrm{N} \eta 1$ of $\mathrm{Arg}^{27}$. This reinforces the interaction between the guanidinium group of this residue and the stretch comprising residues 30-32 (Fig. 5). cis-Pro ${ }^{56}$, found in a short loop between $\mathrm{Cys}^{53}$ and $\mathrm{Cys}^{59}$ has no counterpart in either erabutoxin b or cardiotoxin $\mathrm{V}_{4}^{\mathrm{II}}$ (Table IV). Apparently, this rather tight bend imposes conformational constraints on the proline residue that the trans isomer would be unable to accommodate.

Eighteen out of the 59 water molecules included in the model establish more than one hydrogen bond with atoms of the reference protein molecule (Table V). Their mean $B$ value is $30.7 \AA^{2}$.

\section{Comparison to Other Structurally Related Snake Toxins}

Conservation of Secondary Structure and Loop Regions-As it was observed for the superposition of cardiotoxin $\mathrm{V}_{4}^{11}$ and erabutoxin b (Rees et al., 1987), most of the $\beta$-sheet regions and the disulfide bridges of fasciculin 1 closely match those of the other two toxins (Fig. 7); however, the acetylcholinesterase inhibitor lacks the well defined $\beta$-turns found in erabutoxin $b$ and in cardiotoxin $\mathrm{V}_{4}^{\mathrm{II}}$ at positions 7-10 and 29-32 (fasciculin numbering) (Fig. $3 b$ and Table IV).

Fasciculin 1 and erabutoxin $b$ differ significantly in the orientation of the three central loops (Fig. 7a). The extensive set of interactions that stabilizes loops II and III of fasciculin 1 does not have a counterpart in erabutoxin $b$ where the 
FIG. 5. Stereoscopic view of the interactions between loops II and III of fasciculin 1. Dotted lines depict hydrogen bonds.
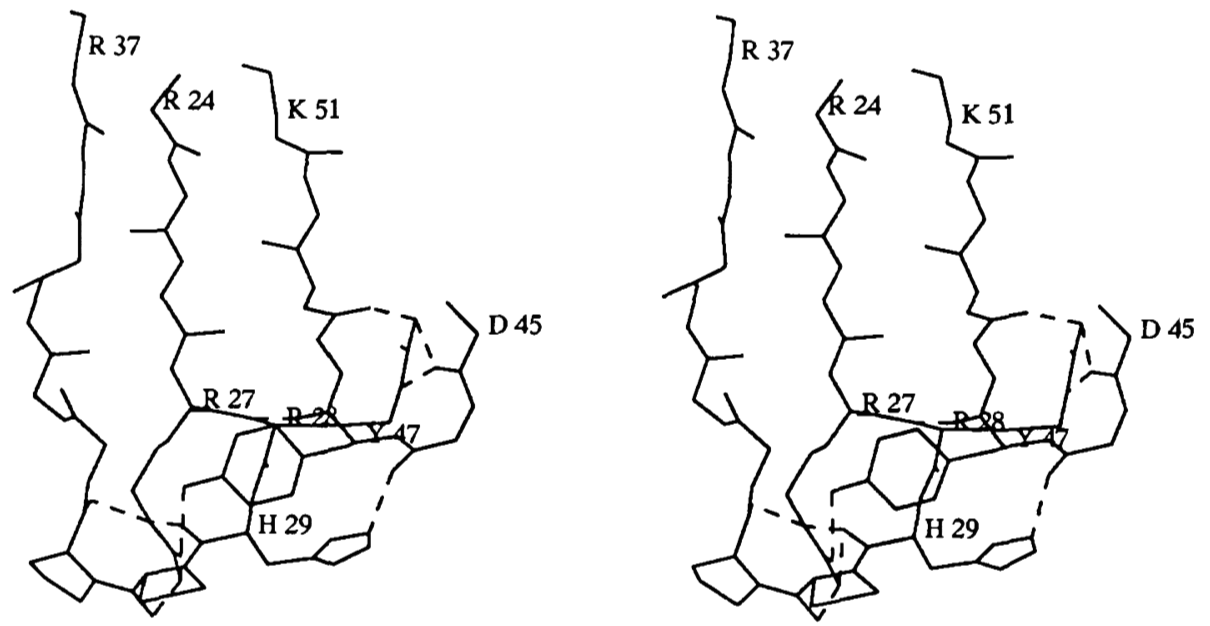

a
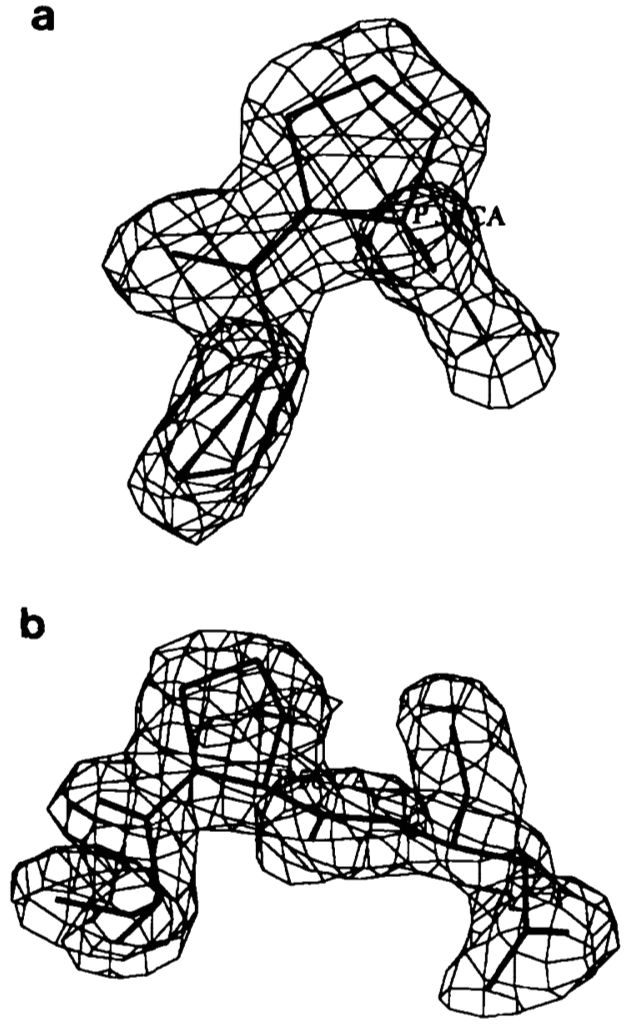
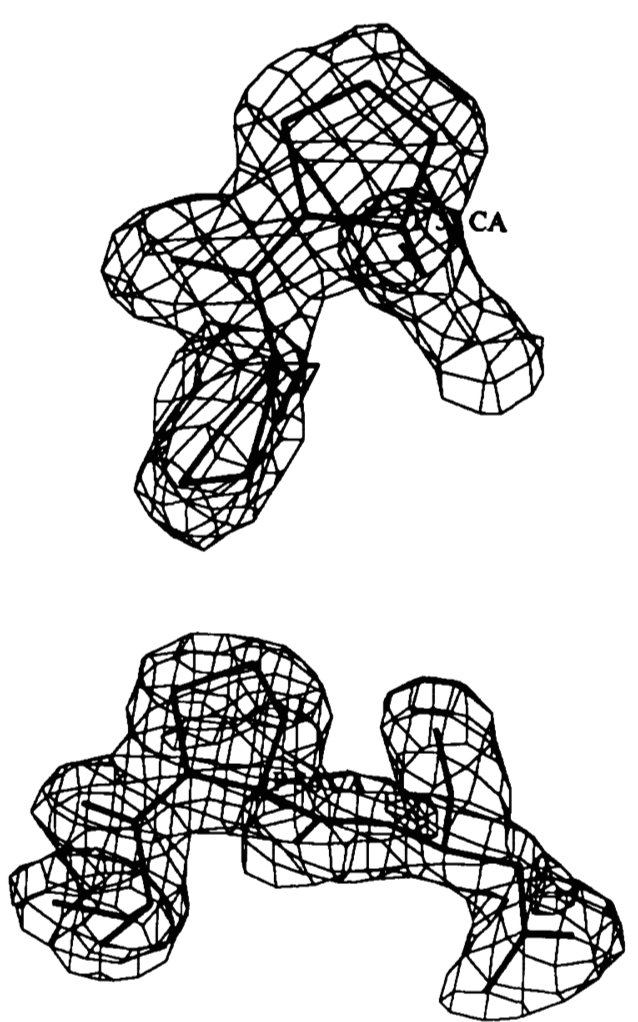

FIG. 6. Stereo view of $(a)$ cis-Pro ${ }^{31}$ and $(b)$ cis-Pro ${ }^{56}$ with the associated electron density. The electron density map was contoured at the $1 \sigma$ level.

region appears potentially more flexible. This is especially true of loop II, which considerably protrudes from the rest of the toxin structure. The comparison of cardiotoxin $\mathrm{V}_{4}^{\mathrm{II}}$ and fasciculin 1 show that they have the same molecular concavity, which is opposed to that of erabutoxin b (Fig. $7 b$ ). In addition, there is a remarkable overall coincidence in the orientation of loops II and III and in the hydrogen bonding defining the local $\beta$-sheet structure. This includes the hydrogen bond connecting $\mathrm{N}$ of $\mathrm{Arg}^{28}$ to $\mathrm{O}$ of $\mathrm{Tyr}^{47}$ (Fig. 5), which is not found in erabutoxin $b$. The nature of the additional interloop contacts varies depending on the toxin. In cardiotoxin $\mathrm{V}_{4}^{\mathrm{II}}$, they are mostly of hydrophobic character and concern the side chains of $\mathrm{Met}^{24}, \mathrm{Leu}^{26}, \mathrm{Leu}^{48}, \mathrm{Val}^{49}$, and $\mathrm{Tyr}^{51}$. In fasciculin 1 , they are predominantly hydrophilic interactions involving side chain-main chain hydrogen bonds between $\mathrm{Arg}^{27}$, $\mathrm{Arg}^{28}$, and $\mathrm{His}^{29}$ on one side and $\mathrm{Asp}^{45}, \mathrm{Asp}^{46}$, and $\mathrm{Glu}^{49}$, on the other (Figs. $3 b$ and 5).

Conserved Core Residues-The conservation of core residues in the snake toxin family has been extensively discussed by several authors (Dufton and Hider, 1991; Endo and Tamiya, 1991). Menez et al. (1992) have made a systematic analysis of both scorpion and snake toxin amino acid sequences and have concluded that snake toxins having the three-fingered folding pattern are characterized by a consensus sequence composed of 8 half-cystines plus $\mathrm{Gly}^{38}$ and $\mathrm{Pro}^{42}$. A more extensive semi-invariant sequence can be defined if conservative changes are introduced (Endo and Tamiya, 1991). Close examination of the three representative short toxins shows that, besides the four disulfide bridges, the snake toxin fold is characterized by a series of core residues that spans the molecule from $\mathrm{Pro}^{42}$ to the $\mathrm{C}$-terminal carboxyl group and that is approximately perpendicular to loop II. In 
TABLE IV

Amino acid sequence comparison of fasciculin 1, erabutoxin b, and cardiotoxin $\mathrm{V}_{4}^{\mathrm{II}}$, based on three dimensional superpositions

Residues underlined with a straight line are implicated in $\beta$-strands, and those depicted with wavy underlines are involved in $\beta$-turns. The first $\beta$-sheet is constituted by strands A and B, the second by strands D-E. These results were obtained using the program DSSP (Kabsch and Sander, 1983). Conserved residues are shown in bold characters. Fasc.1, fasciculin 1; Era.b, erabutoxin b; Card., cardiotoxin $V_{4}^{11}$.

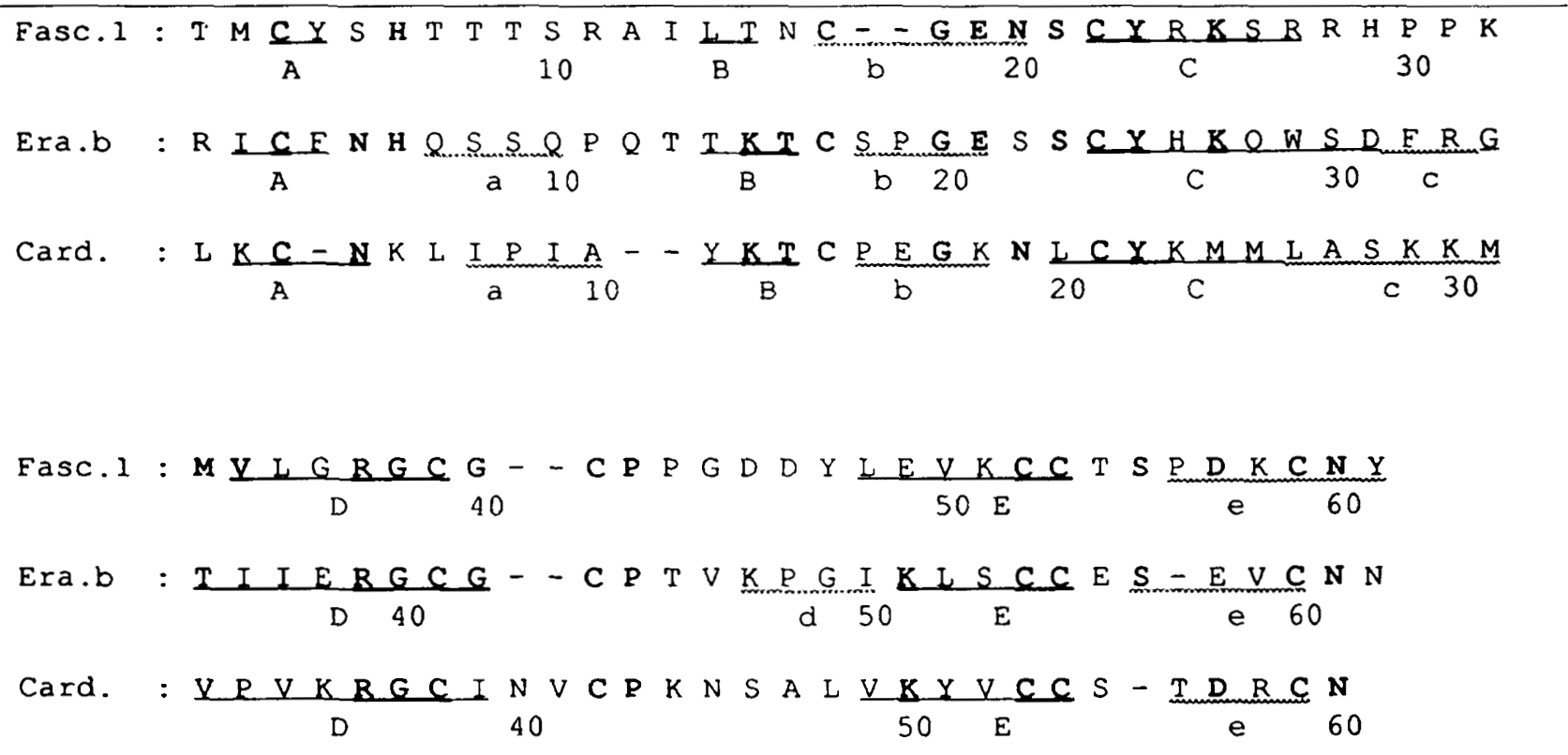

TABLE V

Possible protein-solvent hydrogen bonds

Only those interactions involving 2 protein atoms/solvent molecule are depicted.

\begin{tabular}{|c|c|c|c|c|c|}
\hline $\begin{array}{l}\text { Solvent molecule } \\
\left(B \text {-factor in } \AA^{2}\right)\end{array}$ & Protein & Distance & $\begin{array}{l}\text { Solvent molecule } \\
\left(B \text {-factor in } \AA^{2}\right)\end{array}$ & Protein & Distance \\
\hline \multirow{4}{*}{$\begin{array}{l}62 \\
(43.7)\end{array}$} & & $\AA$ & \multirow{4}{*}{$\begin{array}{l}75 \\
(18.1)\end{array}$} & \multirow{4}{*}{$\begin{array}{l}\mathrm{Ser}^{26}-\mathrm{O} \gamma \\
\mathrm{Arg}^{27}-\mathrm{O} \\
\mathrm{Glu}^{49}-\mathrm{O} \epsilon 1\end{array}$} & $\bar{A}$ \\
\hline & Thr $r^{7}-\mathrm{O}$ & 3.1 & & & 2.5 \\
\hline & $\mathrm{Arg}^{37}-\mathrm{N} \eta 2$ & 3.4 & & & 2.7 \\
\hline & & & & & 2.7 \\
\hline \multirow{3}{*}{$\begin{array}{l}63 \\
(5.4)\end{array}$} & $\mathrm{Thr}^{15}-\mathrm{O} \gamma 1$ & 2.8 & \multirow{5}{*}{$\begin{array}{l}76 \\
(29.1)\end{array}$} & & \\
\hline & $\mathrm{Asn}^{16}-\mathrm{O}$ & 2.9 & & $\mathrm{Arg}^{28}-\mathrm{O}$ & 2.9 \\
\hline & & & & $\mathrm{Lys}^{32}-\mathrm{Nz}$ & 2.8 \\
\hline \multirow{4}{*}{$\begin{array}{c}65 \\
(14.2)\end{array}$} & $\mathrm{Arg}^{24}-\mathrm{N}_{\eta 1}$ & 3.0 & & $\mathrm{Glu}^{49}-\mathrm{O}_{\epsilon} 1$ & 2.7 \\
\hline & $\mathrm{Arg}^{24}-\mathrm{O}$ & 2.8 & & & \\
\hline & $\operatorname{Ser}^{26}-\mathrm{O} \gamma$ & 2.8 & \multirow{3}{*}{$\begin{array}{l}77 \\
(40.5)\end{array}$} & \multirow{3}{*}{$\begin{array}{l}\mathrm{Cys}^{41}-\mathrm{N} \\
\mathrm{Pro}^{42}-\mathrm{N}\end{array}$} & 2.8 \\
\hline & & & & & 3.3 \\
\hline \multirow{3}{*}{$\begin{array}{l}68 \\
(20.9)\end{array}$} & $\operatorname{Ser}^{5}-\mathrm{O}$ & 2.7 & & & \\
\hline & $\mathrm{Arg}^{37}-\mathrm{N}$ & 3.0 & \multirow{2}{*}{$\begin{array}{l}78 \\
(31.4)\end{array}$} & \multirow{2}{*}{$\begin{array}{l}\mathrm{Pro}^{43}-\mathrm{O} \\
\mathrm{Asp}^{45}-\mathrm{O} \delta 1\end{array}$} & 2.7 \\
\hline & $\mathrm{Arg}^{37}-\mathrm{O}$ & 3.0 & & & 2.8 \\
\hline \multirow{3}{*}{$\begin{array}{l}69 \\
(22.5)\end{array}$} & $\mathrm{Thr}^{1}-\mathrm{N}$ & 2.8 & \multirow{3}{*}{$\begin{array}{l}79 \\
(36.3)\end{array}$} & $\operatorname{Arg}^{24}-\mathrm{N}_{\eta 2}$ & 3.3 \\
\hline & $\mathrm{Asn}^{16}-\mathrm{O} \delta 1$ & 2.9 & & $\mathrm{Tyr}^{61}-\mathrm{O}$ & 3.1 \\
\hline & & & & $\mathrm{Tyr}^{61}-\mathrm{OT}$ & 2.8 \\
\hline \multirow{3}{*}{$\begin{array}{l}70 \\
(32.9)\end{array}$} & $\mathrm{Arg}^{24}-\mathrm{N} \eta 1$ & $\begin{array}{l}3.2 \\
3.1\end{array}$ & \multirow{3}{*}{$\begin{array}{l}93 \\
(38.9)\end{array}$} & \multirow{3}{*}{$\begin{array}{l}A_{s p}^{57}-N \\
A_{s p}^{57}-O \delta 1\end{array}$} & \\
\hline & $\mathrm{Arg}^{24}-\mathrm{N} \eta 2$ & $\begin{array}{l}3.1 \\
2.8\end{array}$ & & & 3.4 \\
\hline & Lys ${ }^{20-O}$ & & & & 3.0 \\
\hline \multirow{3}{*}{$\begin{array}{l}71 \\
(13.6)\end{array}$} & $\mathrm{Arg}^{28}-\mathrm{N}$ & 3.2 & \multirow{3}{*}{$\begin{array}{l}94 \\
(36.8)\end{array}$} & \multirow{3}{*}{$\begin{array}{l}\mathrm{Ser}^{5}-\mathrm{N} \\
\mathrm{Ile}^{13}-\mathrm{O}\end{array}$} & 2.9 \\
\hline & $\mathrm{His}^{29}-\mathrm{N}$ & 2.9 & & & 2.6 \\
\hline & $\mathrm{Tyr}^{47}-\mathrm{O}$ & 2.8 & & & \\
\hline \multirow{2}{*}{$\begin{array}{l}73 \\
(22.0)\end{array}$} & $\mathrm{Cys}^{17}-\mathrm{O}$ & 3.0 & \multirow{2}{*}{$\begin{array}{l}96 \\
(47.8)\end{array}$} & \multirow{2}{*}{$\begin{array}{l}\mathrm{Arg}^{28}-\mathrm{N} \eta 1 \\
\mathrm{Glu}^{49}-\mathrm{O} \epsilon 2\end{array}$} & \multirow{2}{*}{$\begin{array}{l}3.1 \\
3.3\end{array}$} \\
\hline & $\mathrm{Asn}^{20}-\mathrm{O} \delta 1$ & 3.3 & & & \\
\hline \multirow{3}{*}{$\begin{array}{c}74 \\
(36.4)\end{array}$} & & & \multirow{3}{*}{$\begin{array}{l}99 \\
(61.9)\end{array}$} & $\mathrm{Val}^{34}-\mathrm{N}$ & 2.9 \\
\hline & $\mathrm{Arg}^{24}-\mathrm{N} \eta 2$ & 3.1 & & \multirow[t]{2}{*}{$\mathrm{Val}^{34}-\mathrm{O}$} & \multirow{2}{*}{2.8} \\
\hline & $\mathrm{Tyr}^{61}-\mathrm{O}$ & 2.9 & & & \\
\hline
\end{tabular}



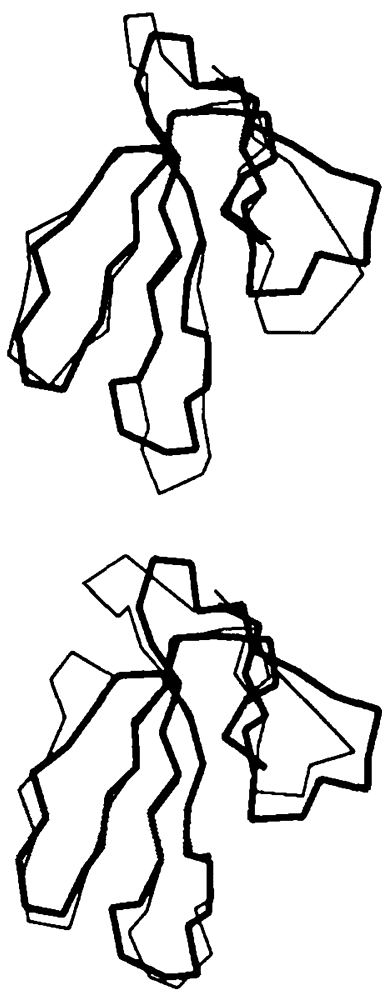
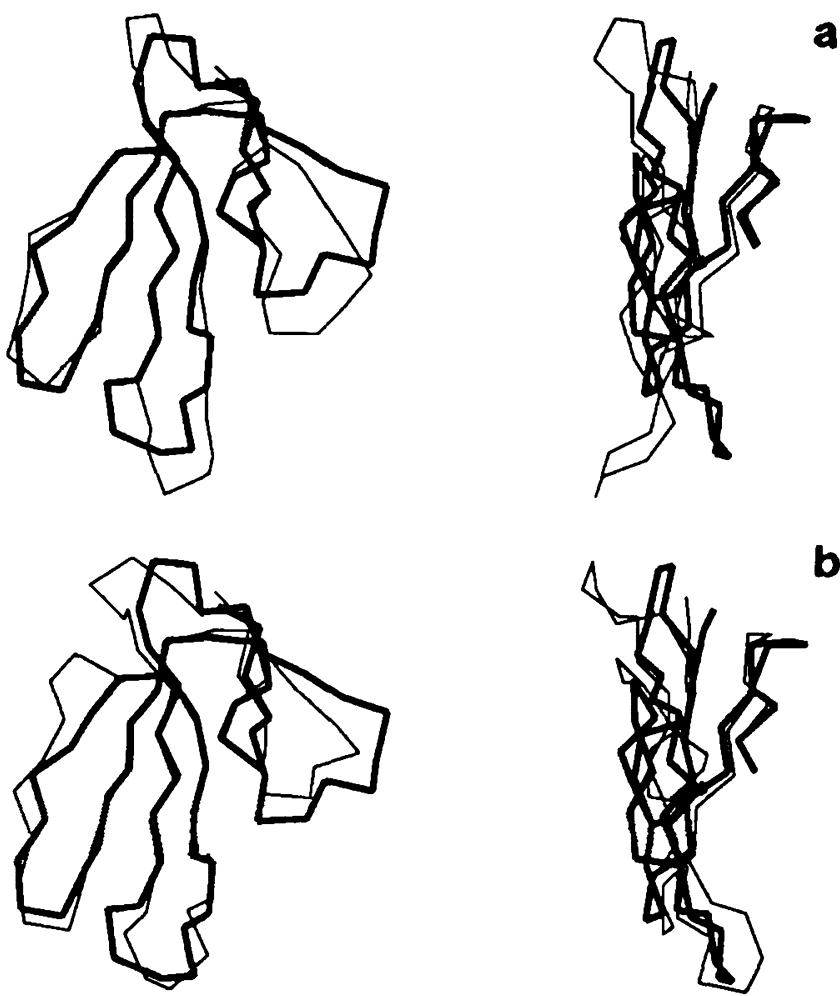

a

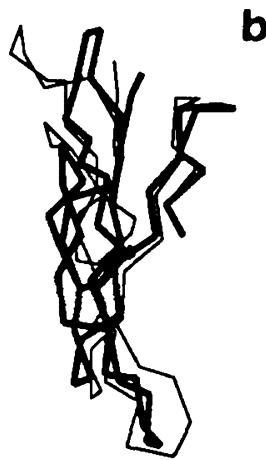

FIG. 7. Stereo drawing depicting (a) the superposition of fasciculin 1 (thick line) and erabutoxin b and (b) the superposition of fasciculin 1 and cardiotoxin $3 V_{4}^{\mathrm{II}}$. The three models were superimposed by using the topologically equivalent $\mathrm{C}_{\alpha} \mathrm{s}$ contained in the three-stranded $\beta$-sheet (see Table IV). Monographic views, rotated by $90^{\circ}$ relative to their stereo counterparts, are also shown.

fasciculin 1 and erabutoxin $b$, the stretch is identical and consists of $\mathrm{Pro}^{42}, \mathrm{Tyr}^{23}, \mathrm{Lys}^{25}, \mathrm{Gly}^{38}, \mathrm{Arg}^{37}$, and $\mathrm{Asn}^{60}$ (fasciculin numbering) and the C-terminal carboxylate (Fig. $8 a$ ). All but one of the interactions around the $\mathrm{C}$-terminal region of fasciculin 1 are also preserved in cardiotoxin $\mathrm{V}_{4}^{\mathrm{II}}$. However, the environment around the conserved tyrosine residue is somehow different; the intrusion of $\mathrm{Ile}^{39}$ displaces $\mathrm{Pro}^{43}$, whereas $\mathrm{Lys}^{25}$ and $\mathrm{Val}^{50}$ are replaced by $\mathrm{Met}^{24}$ and $\mathrm{Tyr}^{51}$, respectively (Fig. $8 b$ ).

The overall similarity of fasciculin 1 to erabutoxin b and cardiotoxin $\mathrm{V}_{4}^{\mathrm{II}}$ has been evaluated by rigid body least squares superposition of their $\mathrm{C}_{c} \mathrm{~s}$ according to the alignment of Table IV. The obtained root mean square deviations are $1.6 \AA$ for the fasciculin 1-cardiotoxin $\mathrm{V}_{4}^{\mathrm{II}}$ pair and $2.3 \AA$ for the fasciculin 1-erabutoxin b pair.

\section{DISCUSSION}

The crystallographic analysis of fasciculin 1 , a potent acetylcholinesterase inhibitor, shows that this molecule, as suggested by its amino acid sequence, is representative of a third group of snake toxins structurally close to both $\alpha$-neurotoxins and cardiotoxins. All these molecules share a fold characterized by a dense core that contains four disulfide bridges and three long loops disposed as the central fingers of a hand. In the crystal structure of fasciculin 1 there is a marked difference between the level of organization of the three central loops. Loop I appears poorly defined, and its residues display high temperature factors. Loops II and III, in turn, establish a series of interactions, both as part of the $\beta$-sheet structure and as hydrogen bonding involving side and main chain atoms. Although this $\beta$-sheet stretch has the same bonding pattern as its counterpart in cardiotoxin $\mathrm{V}_{4}^{\mathrm{II}}$, the other interactions are characteristic of fasciculin 1 . The disposition of the core residues of all the members of the three-finger type toxins shows that the closest fit is obtained when comparing fasciculin 1 and erabutoxin $b$.

It is of interest to consider fasciculins within the context of snake toxin phylogeny. To this date, two main hypotheses have been postulated concerning the evolution of these proteins. The first one is best represented by Strydom (1979) who has concluded that an ancestral "cardiotoxin-phospholipase" led to the cardiotoxins, on the one hand, and from a short neurotoxic ancestor to long and then short $\alpha$-neurotoxins on the other. A somewhat similar view has been proposed by Ivanov and Ivanov (1979). The second approach has been advocated by Dufton (1984) and Dufton and Harvey (1989), who have used an intercystine loop length analysis to divide the three-finger type snake toxins into several groups and to establish a dendrogram carrying evolutionary implications. Short $\alpha$-neurotoxins and cardiotoxins have similar intercystine loop lengths, but whereas the former are extensively distributed in elapid venoms, the latter are only found in cobras and ringhals. Based on these observations, Dufton (1984) has concluded that cardiotoxicity evolved from an ancestral neurotoxic capability. Both propositions place the "angusticeps-type" toxins, such as fasciculins, closer to the $\alpha$ neurotoxins than to cardiotoxins. There are, however, significant amino acid sequence differences between neurotoxins and fasciculins. Noting this, Strydom (1977) has proposed that evolutionary change has taken place faster in the "angusticeps-type" toxins than in $\alpha$-neurotoxins from the same venoms.

As mentioned above, although it was not immediately obvious from amino acid sequence data, the three-dimensional structure of fasciculin 1 reveals characteristics that are intermediate between those of erabutoxin $b$ and cardiotoxin $V_{4}^{I I}$. Since, in general, a three-dimensional structure is considered to be more conserved than amino acid sequence (Johnson et al., 1990), the overall structure of fasciculin 1 should shed new light on the phylogenetic relationships of snake toxins having the three-finger pattern; if, as it has been proposed, 

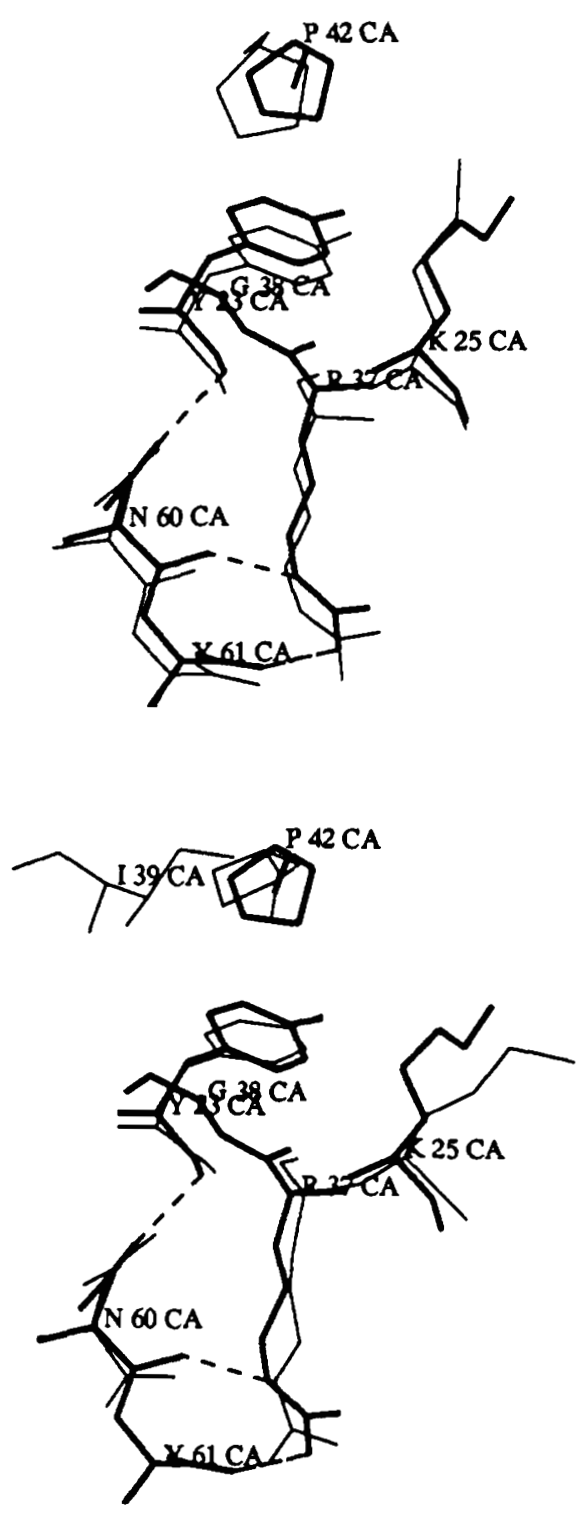
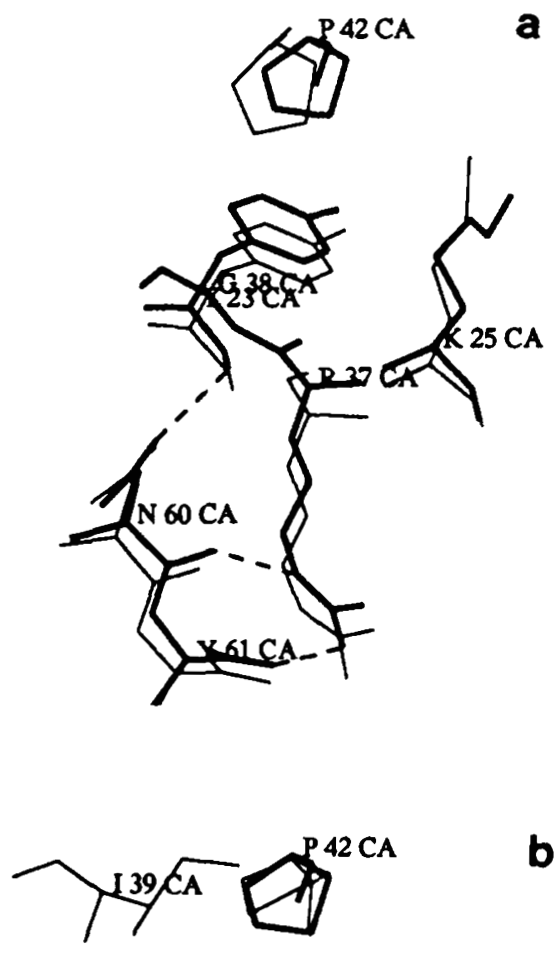

b

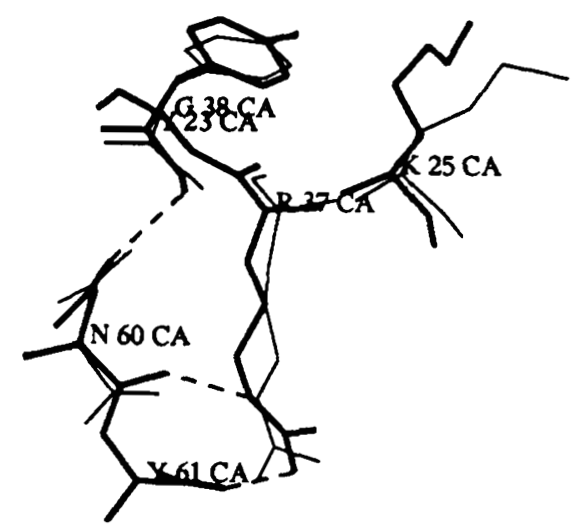

FIG. 8. Stereo drawing of the environment around $\mathbf{T y} \mathbf{r}^{23}$. Comparison of (a) fasciculin 1 (thick line) and erabutoxin $\mathrm{b}$ and (b) fasciculin 1 and cardiotoxin $\mathrm{V}_{4}^{11}$. The superposition was done as described in the legend to Fig. 6 . In $b$, the side chain of $\mathrm{Tyr}^{51}$ has been omitted for clarity.

fasciculins are more closely related to $\alpha$-neurotoxins than to cardiotoxins, then the similar hydrogen bonding schemes and orientations of loops II and III observed in cardiotoxin $\mathrm{V}_{4}^{\mathrm{II}}$ and fasciculin 1 are the result of convergent evolution. Convergent, or parallel, evolution following divergency from a common ancestral gene has been found in other protein families (Stewart et al., 1987; Kuriyan et al., 1991). Alternatively, and if fasciculins turn out to be more closely related to cardiotoxins than to $\alpha$-neurotoxins, then current thoughts about snake toxin evolution will have to be revised. More light will be shed on this problem as novel snake toxin structures of the three-finger type become available.

The crystal structure of acetylcholinesterase from Torpedo californica has been recently determined (Sussman et al., 1991). The active site of the esterase is known to be located in a deep and narrow gorge that is partially lined by 14 aromatic residues, but the exact location of the peripheral site, to which fasciculins bind, has not yet been determined. The aromatic character of the region neighboring the active site and the fact that several small molecules that bind to the secondary site of acetylcholinesterase have quaternary am- monium groups (Taylor and Lappi, 1975; Dougherty and Stauffer, 1990) suggests that basic side chains are involved in the binding of the toxin to the esterase. In fasciculin 1, several arginine and lysine side chains are clustered around the tip of loop II ( $\mathrm{Arg}^{27}, \mathrm{Arg}^{28}$, and $\mathrm{Lys}^{32}$ ) and on the concave region of the molecule $\left(\mathrm{Arg}^{24}, \mathrm{Arg}^{37}\right.$, and $\mathrm{Lys}^{51}$ ). It is conceivable that one or both of these clusters could be involved in the binding. The simultaneous contribution of several positively charged groups to complex formation would be in agreement with the fact that only partial loss of inhibitory activity is observed upon chemical modification of certain arginine or lysine side chains of fasciculins (Cerveñanski et al., 1991b).

It would be of interest to prepare crystals of a complex between acetylcholinesterase and fasciculin, as this would allow the detailed study of the interaction of a small protein toxin with its solubilized receptor.

Acknowledgments-We thank Prof. H. Rochat and Dr. A. Menez for encouragement and fruitful discussions. REFERENCES

Betzel, C., Lange, G., Pal, G. P., Wilson, K. S., Maelicke, A., and Saenger, W. (1991) J. Biol. Chem., 266, 21530-21536 
Bougis, P. E., Rochat, H., Piëroni, G., and Verger, R. (1981) Biochemistry 20, 4915-4920

Blundell T. L., and Johnson L. N. (1976) Protein Crystallography, pp. 337-362, Academic Press, New York

Brünger, A. T. (1988) in Crystallographic Computing 4: Techniques and New Technologies (Isaacs, N. W., and Taylor, M. R., eds) pp. 126-140, Charendon Technologies

Press, Oxford
Cerveñanski, C., Dajas, F., Harvey, A. L., and Karlsson, E. (1991a) in Snake Toxins (Harvey, A. L., ed) pp. 303-321, Pergamon Press, New York

Cerveñanski, C., Engström, A., and Karlsson, E. (1991b) Toxicon 29, 1163

Changeux, J. P., Kasai, M., and Lee, C.-Y. (1970) Proc. Natl. Acad. Sci. U. S. A 67, $1241-1247$

Dodson, E. (1976) in Crystallographic Computing Techniques (Ahmed, F. R., ed) pp. 259-268, Munksgaard, Copenhagen

Dougherty, D. A., and Stauffer D. A. (1990) Science 250, 1558-1560

Dougherty, D. A., and Stauffer D. A. (1990) Science 250, 1558-1560

Snake Toxins (Harvey, A. L., ed) pp. 385-414, Pergamon Press, New York

Dufton, M. J. (1984) J. Mol. Evol. 20, 128-134

Dufton, M. J., and Harvey, A. L. (1989) Trends Pharmacol. Sci. 10, 258-259

Dufton, M. J., and Hider, R. C. (1983) CRC Crit. Rev. Biochem. 14, 113-171

Dufton, M. J., and Hider, R. C. (1991) in Snake Toxins (Harvey, A. L., ed) pp. 259-302, Pergamon Press, New York

Endo, T., and Tamiya, N. (1987) Pharmacol. Ther. 34, 403-451

Endo, T., and Tamiya, N. (1991) in Snake Toxins (Harvey, A. L., ed) pp. 165 222, Pergamon Press, New York

222, Pergamon Press, New York
Fontecilla-Camps, J. C. (1989) J. Mol. Evol. 29, 63-67

Fontecilla-Camps, J. C. (1989) J. Mol. Evol. 29, 63-6
Harvey, A. L. (1985) J. Toxicol. Toxin Rev. 4, 41-49

Harvey, A. L., Anderson, A. J., Mbugua, P. M., and Karlsson, E. (1984) J Toxicol. Toxin Rev. 3, 91-137

Howard, A. J., Gilliland, G. L., Finzel, B. C., Poulos, T. L., Olhendorf, D. H., and Salemme, F. R. (1987) J. Appl. Crystallogr. 20, 383-387

Ivanov, Ch. P., and Ivanov, O. Ch. (1979) Toxicon 17, 205-220

Johnson, M. S., Sali, A., and Blundell, T. L. (1990) in Methods Enzymol. 183, 670-694

Joubert, F., and Taljaard, N. (1978) S. Afr. J. Chem. 31, 107-110

Kabsch, W., and Sander, C. (1983) Biopolymers 22, 2577-2637

Karlsson, E., Mbugua, P. M., and Rodriguez-Ithuralde, D. (1984) J. Physiol. (Paris) 79, 232-240

Kuriyan, J., Krishna, T. S. R., Wong, L., Guenter, B., Pahler, A., Williams, C. H., Jr. and Model, P. (1991) Nature 352, 172-174

Labhardt, A. M., Hunziker-Kwik, E. H., and Wüthrich, K. (1988) Eur. J. Biochem. 177, 295-305

Laplante, S. R., Mikou, A., Robin, M., Guittet, E., Delsuc, M., Charpentier, I., and Lallemand, J. Y. (1990) Int. J. Pept. Protein Res. 36, 227-230

le Du, M. H., Marchot, P., Bougis, P., and Fontecilla-Camps, J. C. (1989) J Biol. Chem., 264, 21401-21402

Love, R. A., and Stroud, R. M. (1986) Protein Eng. 1, 37-46
Low, B., Preston, H. S., Sato, A., Rosen, L. S., Searl, J. E., Rudko, A. D., and Richardson, J. S. (1976) Proc. Natl. Acad. Sci. U. S. A 73, 2991-2994

Luzzati, P. V. (1952) Acta Crystallogr. 5, 802-810

Machin, P. A., Wonacott, A. J., and Moss, D. (1984) Daresbury Lab. News 13, 17-19

Matthews, B. W. (1968) J. Mol. Biol. 33, 491-497

Ménez, R., and Ducruix, A. (1990) J. Mol. Biol. 216, 233-234

Mènez, A., Gatineau, E., Roumestand, C., Harvey, A. L., Mouawad, L., Gilquin, B., and Toma, F. (1990) Biochimie (Paris) 72, 575-588

Ménez, A., Bontems, F., Roumestand, C., Gilquin, B., and Toma, F. (1992) in The Advancement of Drug Discovery (Harvey, A. L., ed) Royal Society of Edinburgh, in press

Oswald, R. E., Sutcliffe, M. J., Bamberger, M., Loring, R. H., Braswell, E., and Dobson, C. M. (1991) Biochemistry 30, 4901-4909

Ramachandran, G. N., and Mitra, A. K. (1976) J. Mol. Biol. 107, 85-92

Rees, B., Samama, J. P., Thierry, J. C., Gilibert, M., Fischer, J., Schweitz, H., Rees, B., Samama, J. P., Thierry, J. C., Gilibert, M., Fischer, J., Schweitz, H., Rees, B
Ladzun
3138
Rees,

Rees, B., Bilwes, A., Samama, J. P., and Moras, D. ( 1990 ) J. Mol. Biol. 214, $281-297$

Richardson, J. (1981) Adv. Protein Chem. 34, 167-339

Rodriguez-Ithurralde, D., Silveira, L., Barbeito, L., and Dajas, F. (1983) Neurochem. Int. 5, 267-274

Roussel, A., and Cambillau, C. (1989) in Silicon Graphics Geometry Partner Directory (Silicon Graphics, ed) Fall, pp. 77-78, Silicon Graphics, Mountain Directory $\mathrm{CA}$

Sankar, P., Basu, L. I. H., and Ward, K. B. (1989) Toxicon 27, 832

Schulz, G. E., and Schirmer, R. H. (1979) in Principles of Protein Structure (Cantor, C. R., ed) pp. 74-75, Springer-Verlag, New York

Smith, J. L., Corfield, P. W. R., Hendrickson, W. A., and Low, B. (1988) Acta Crystallogr. Sect. A Cryst. Phys. Diffr. Theor. Gen. Crystallogr. 44, 357-368

Steinmetz, W. E., Bougis, P. E., Rochat, H., Redwine, O. D., Braun, W., and Wüthrich, K. (1988) Eur. J. Biochem. 172, 101-116

Stewart, C.-B., Schilling, J. W., and Wilson, A. (1987) Nature 330, 401-404

Stewart, C.-B., Schilling, J. W., and Wilson, A. (1987)

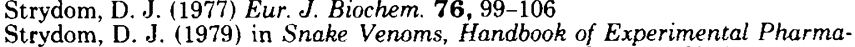
cology (Lee, C. Y., ed) Vol. 52, pp. 159-212, Berlin, Springer-Verlag

Sussman, J. L., Harel, M., Frolow, F., Oefner, C., Goldman, A., Toker, L., and Silman, I. (1991) Science 253, 872-879

Taylor, P., and Lappi, S. (1975) Biochemistry 14, 1989-1997

Tsernoglou, D., and Petsko, G. A. (1976) FEBS Lett. 68, 1-4

Viljoen, C. C., and Botes, D. P. (1973) J. Biol. Chem. 248, 4915-4919

Wang, B. C. (1985) Methods Enzymol. 115, 90-112

Wlodawer, A., and Hodgson, K. O. (1975) Proc. Natl. Acad. Sci. U. S. A., 72, 398-399

Yu, C., Lee, C.-S., Chuang, L.-C., Shei, Y.-R., and Wang, C. Y. (1990) Eur. J. Biochem. 193, 789-799 